\title{
Determination of polybrominated diphenyl ethers in human semen
}

\author{
Peng-Yan Liu ${ }^{a}$, Ya-Xian Zhao ${ }^{b}$, Yi-Yang Zhu ${ }^{c}$, Zhan-Fen Qin ${ }^{b}, *$, Xian-Li Ruan ${ }^{c}$, Yong-Chuan Zhang ${ }^{c}$, \\ Bao-Jun Chen ${ }^{c}$, Yan Li ${ }^{\text {b }}$, Shi-Shuai Yan ${ }^{\text {b }}$, Xiao-Fei Qin ${ }^{\text {b }}$, Shan Fu ${ }^{\text {b }}$, Xiao-Bai Xu ${ }^{\text {b }}$ \\ a College of Chemistry and Environmental Science, HeBei University, Baoding, Hebei, China \\ b State Key Laboratory of Environmental Chemistry and Ecotoxicology, Research Center for Eco-environmental Sciences, Chinese Academy of Sciences, Beijing, China \\ c Taizhou Hospital, Taizhou, Zhejiang, China
}

\section{A R T I C L E I N F O}

Available online 12 June 2011

\section{Keywords:}

Polybrominated diphenyl ethers

Human

Semen

Blood

Non-invasive matrix

\begin{abstract}
A B S T R A C T
Some persistent organic pollutants (POPs) have been found in human semen but until this point it was unclear whether polybrominated diphenyl ethers (PBDEs) could be detected in human semen. In this study, PBDEs were found for the first time in human semen samples $(\mathrm{n}=101)$ from Taizhou, China. The concentrations of total PBDEs ( $\sum$ PBDEs) varied from 15.8 to $86.8 \mathrm{pg} / \mathrm{g}$ ww (median $=31.3 \mathrm{pg} / \mathrm{g} \mathrm{ww}$ ) and 53.2 to $121 \mathrm{pg} / \mathrm{g}$ ww (median $=72.3 \mathrm{pg} / \mathrm{g} \mathrm{ww}$ ) in semen and blood samples, respectively. The $\sum$ PBDE level in semen was about two times lower than in human blood, which was different in the distribution in the two matrices from other POPs. A correlation of $\sum$ PBDE concentration was found between paired semen and in blood. The results suggest that semen could be used to detect PBDE burden in human body as a non-invasive matrix. In addition, the levels of BDE-209 and BDE-153, especially the latter, were much higher in blood than in semen, while the levels of BDE-28, BDE-47 and BDE-99 were comparable in the two matrices, suggesting that low brominated congeners could be more easily transferred to semen than high brominated congeners. Considering different toxicities among the PBDE congeners, it might be more significant to measure PBDEs in semen than in blood for evaluating male reproduction risks of PBDEs.
\end{abstract}

(c) 2011 Elsevier Ltd. All rights reserved.

\section{Introduction}

Polybrominated diphenyl ethers (PBDEs) have been widely used for many years as flame retardants in a variety of commercial products such as electronics, furniture, and textiles. PBDEs are a class of ubiquitous pollutants that have received much attention due to bioaccumulation and potential toxicity. PBDEs have been detected in some human samples including fat, blood, breast milk, etc. (Antignac et al., 2009; Aylward et al., 2003; Bi et al., 2007; Zhao et al., 2010). Previous studies have shown that some lipophilic contaminants, such as polychlorinated biphenyls (PCBs), dioxins and certain pesticides, are able to enter into human semen (Ensslen et al., 1990; Schlebusch et al., 1989; Schmid et al., 1993; Stachel et al., 1989; Szymczynski and Waliszewski, 1981; Trapp et al., 1984). Semen as a non-invasive matrix can be used to measure the human burden of these POPs. Several reports on laboratory animals showed that PBDEs might affect male reproductive health by interfering with the sex-hormone functions (Fowles et al., 1994; Zhou et al., 2002). However, whether PBDEs are present in human semen and whether semen can be used as matrix to measure the human burden of PBDEs have not been explored.

\footnotetext{
* Corresponding author at: P.O. Box 2871, Research Center for Eco-Environmental Sciences, Chinese Academy of Sciences, Beijing, 100085, China. Tel.: +86 1062919177 ; fax: + 861062923563 .

E-mail address: qinzhanfen@rcees.ac.cn (Z.-F. Qin).
}

Taizhou region in Zhejiang Province is one of the largest electricwaste (e-waste) recycling areas in China, where a mass of e-wastes from abroad as well as home are recycled using primitive methods, resulting in heavy PBDE pollution in the environment. In addition, plastic manufacture as a dominant industry in Taizhou might also contribute to PBDE pollution in this region. In our previous studies, high concentrations of PBDEs were found in soils, sediments and biotic samples from some e-waste recycling sites in Taizhou (Liang et al., 2008; Yang et al., 2008; Zhao et al., 2009, 2010). Correspondingly, Zhao et al. (2008) reported high levels of PBDEs in human hair from local residents. We also recently found that PBDE levels in blood from local residents in e-waste recycling sites were also higher than the values from general populations, even U.S. populations (Zhao et al., 2010). In this pilot study, thus, we selected Taizhou population to investigate whether PBDEs can enter into human semen and to confirm the usability of semen as a matrix to indicate PBDE burden in human body.

\section{Material and methods}

\subsection{Sample collection}

We collected semen samples, which were remainders after sperm analysis of male clinic patients, from the Fertility Clinic at Reproductive Health Center of Taizhou Hospital in October-December 2008. To 
ensure the detection of PBDEs, we mixed each 4-5 samples among 87 semen samples into a pooled sample with a volume of approximately $10 \mathrm{~mL}$. So, 19 pooled semen samples were obtained. To compare PBDE concentrations between semen and blood, we collected semen and blood samples of 38 patients from the Fertility Clinic at Reproductive Health Center of Taizhou Hospital in January 2009, and only 14 paired semen/blood samples were obtained. These patients were asked to complete a form regarding their age, stature, weight and abstinence time. Informed consent was obtained from each patient. The information about the patients who provided paired samples of semen and blood was shown in Table 1. All the samples were transported to the laboratory in an ice box and stored at $-20^{\circ} \mathrm{C}$ and darkness until analysis.

\subsection{Chemicals}

A standard solution of PBDE congeners (EO-5278) (Cambridge Isotope Laboratories, USA) was used to quantify BDE-28, 47, 99, 100, 153, 154, 183, and 209. BDE-71 and ${ }^{13}$ C-labled BDE-209 (Cambridge Isotope Laboratories) were used as internal surrogate standards. All solvents and other reagents used in these experiments were of pesticide grade.

\subsection{Extraction and clean-up}

A detailed description of the methods used for extraction has been published elsewhere (Hovander et al., 2000). Procedures for semen and blood samples were the same. Briefly, surrogate standards (BDE$71,{ }^{13} \mathrm{C}$-labled BDE-209) were spiked to the samples in a centrifuge tube, vortexed and then left to equilibrate overnight. Hydrochloric acid and isopropanol were added to denaturize the proteins and release the lipids and the organohalogen compounds. Each sample had rigorous blending between the additions. The analytes were subsequently extracted more than twice with hexane/methyl t-butyl ether (MTBE; 1:1). The combined organic phases were washed with a potassium chloride water solution, followed by evaporation to dryness for gravimetric determination of extracted lipid content. The analytes and lipids were redissolved in hexane. The concentrated extract was cleaned by passing through a $15-\mathrm{mm}$ i.d. column, which was packed, from the bottom to top, with $1 \mathrm{~g}$ activated silica gel, $8 \mathrm{~g}$ acid silica gel ( $40 \%$ concentrated sulfuric acid, w/w), $1 \mathrm{~g}$ activated silica gel, and $1 \mathrm{~cm}$ anhydrous sodium sulfate. The extract was eluted with $100 \mathrm{~mL}$ of hexane, concentrated to $2 \mathrm{~mL}$ using a rotary evaporator. Finally, the analytes were concentrated to approximately $0.1 \mathrm{~mL}$ under a gentle nitrogen stream and then transferred to GC vials. Throughout the extraction, cleanup and analysis procedures, the analytes were protected from light by wrapping the containers with aluminum foil or by using amber glassware.

Table 1

Demographic characteristic of patients who provided paired samples.

\begin{tabular}{llllllr}
\hline Samples & Area & Stature & Weight & BMI* $^{*}$ & Age & Abstinence time (days) \\
\hline Sample 1 & Ruban & 178 & 70 & 22.09 & 29 & 10 \\
Sample 2 & Urban & 169 & 64 & 22.41 & 29 & 3 \\
Sample 3 & Rural & 170 & 60 & 20.76 & 33 & 10 \\
Sample 4 & Rural & 167 & 60 & 21.51 & 35 & 8 \\
Sample 5 & Urban & 176 & 73 & 23.57 & 26 & 30 \\
Sample 6 & Rural & 175 & 72 & 23.51 & 33 & 7 \\
Sample 7 & Urban & 170 & 65 & 22.49 & 31 & 11 \\
Sample 8 & Rural & 172 & 60 & 20.28 & 28 & 1 \\
Sample 9 & Rural & 170 & 52 & 17.99 & 20 & 4 \\
Sample 10 & Urban & 170 & 72 & 24.91 & 32 & 4 \\
Sample 11 & Urban & 180 & 90 & 27.78 & 32 & 11 \\
Sample 12 & Urban & 166 & 63 & 22.86 & 34 & 4 \\
Sample 13 & Urban & 170 & 62 & 21.45 & 32 & 7 \\
Sample 14 & Rural & 171 & 64 & 21.89 & 31 & 12 \\
\hline
\end{tabular}

BMI: body mass index.

\subsection{Gas chromatography-mass spectrometry}

The samples were analyzed by an Agilent 6890 series gas chromatograph coupled to an Agilent 5973 mass spectrometer using negative chemical ionization $(\mathrm{NCI})$ with the selected-ion monitoring mode (SIM). A $1 \mu \mathrm{L}$ sample was injected in splitless mode onto a DB-5 MS (15 $\mathrm{m} \times 0.25 \mathrm{~mm}$ i.d., $0.25 \mu \mathrm{m}$ film thickness) fused silica capillary column with helium as carrier gas at a constant flow rate of $1 \mathrm{~mL} / \mathrm{min}$. The ion source and interface temperatures were set to $150{ }^{\circ} \mathrm{C}$ and $300{ }^{\circ} \mathrm{C}$, respectively. The GC oven temperature program was carried out as follows: started at $80^{\circ} \mathrm{C}$, held for $1 \mathrm{~min}$, increased to $200{ }^{\circ} \mathrm{C}$ at $10^{\circ} \mathrm{C} / \mathrm{min}$, and then to $300{ }^{\circ} \mathrm{C}$ at $20^{\circ} \mathrm{C} / \mathrm{min}$, held for $20 \mathrm{~min}$. Ion fragments $\mathrm{m} / \mathrm{z} 79$ and 81 were monitored for tri- to hepta-BDE congeners, $\mathrm{m} / \mathrm{z}$ 488.6, 486.6 for BDE-209 and 492.6, 494.6 for ${ }^{13}$ C-labled BDE-209.

\section{5. $Q A / Q C$}

Analytical quality control was applied during analysis. The continuous monitoring of laboratory contamination was conducted based on the determination of a blank sample throughout the whole analytical procedure, including extraction, cleanup, and quantification. A procedural blank was run in parallel with every batch of samples. Simultaneously, the ongoing precision was performed, and the recoveries of surrogate standards BDE-71/ $/{ }^{13} \mathrm{C}$-labled BDE-209 averaged $86 \pm 12 \% / 54 \pm 9 \%$ in semen and $71 \pm 6 \% / 68 \pm 16 \%$ in blood, respectively. Analyte values were corrected for recovery. The detection limits (LOD), defined as a signal of three times the noise level, were in the range of $0.09-0.26 \mathrm{pg} / \mathrm{g}$ wet weight ( $\mathrm{ww}$ ) for tri- to hepta-BDEs and $0.97 \mathrm{pg} / \mathrm{g}$ ww for deca-BDE in semen, and 0.12 $0.24 \mathrm{pg} / \mathrm{g}$ ww for tri- to hepta-BDEs and $1.21 \mathrm{pg} / \mathrm{g}$ ww for deca-BDE in blood. Non-detect or below LOD values were estimated as half of the detection limit for the purpose of calculating totals, means and medians. The average lipid contents of semen and blood samples were approximately $0.33 \%$ and $0.45 \%$, respectively.

\subsection{Statistical analysis}

For comparison of the concentrations of PBDEs in paired samples of semen and blood, the nonparametric Wilcoxon rank-sum test was used. Correlations of PBDE concentrations between paired semen and blood samples were tested using the Pearson coefficient of determination. Relationships between PBDE levels and the parameters of patient information were investigated using Spearman non-parametric correlation. Statistical analysis was performed using the statistical software program SPSS ${ }^{13.0}$ for Windows (SPSS Inc.). The level of significance was set at $\mathrm{p}<0.05$ (two tailed).

\section{Results and discussion}

\subsection{PBDE concentration in human semen compared with in human blood}

PBDEs were detected in all samples from Taizhou of Zhejiang in China, indicating that PBDEs were ubiquitous environmental contaminants in Taizhou region. The concentrations of PBDE congeners as well as total PBDEs ( $\sum$ PBDEs) in the semen and blood were shown in Table 2. The PBDE levels in pooled samples (mean $=35.8 \mathrm{pg} / \mathrm{g}$ ww) were consistent with the paired semen samples (mean $=37.4 \mathrm{pg} / \mathrm{g} \mathrm{ww}$ ). The $\sum$ PBDE concentrations varied from 15.8 to $86.8 \mathrm{pg} / \mathrm{g}$ ww and 53.2 to $121 \mathrm{pg} / \mathrm{g}$ ww in 33 semen samples and 14 blood samples, with median values of $31.3 \mathrm{pg} / \mathrm{g}$ ww and $72.3 \mathrm{pg} / \mathrm{g}$ ww, respectively.

There are several reports regarding the presence of some POPs, such as dioxins, dibenzofurans, and the dioxin-like PCBs, organochlorinated pesticides, in semen or seminal plasma (Kumar et al., 2000; Pant et al., 2007; Schecter et al., 1996; Younglai et al., 2002). In the present study, we found for the first time the presence of PBDEs in human semen and demonstrated that PBDEs could enter human semen like other POPs. In the literature, levels of all detected POPs in blood were much higher than those in semen. Dallinga et al. (2002) reported that $\sum$ PCBs in blood and seminal plasma samples were $1.17 \mathrm{ng} / \mathrm{mL}$ and $0.056 \mathrm{ng} / \mathrm{g}$, respectively. Magnusdottir et al. (2005) reported the concentrations of p,p'-DDE in semen were on average $\sim 40$ times lower than the concentrations in plasma. In our study, however, the mean concentrations of 
Table 2

PBDE concentrations in human semen and blood samples, pg/g ww.

\begin{tabular}{|c|c|c|c|c|c|c|c|c|c|}
\hline & BDE-28 & BDE-47 & BDE-100 & BDE-99 & BDE-154 & BDE-153 & BDE-183 & BDE-209 & $\sum \mathrm{PBDE}_{8}$ \\
\hline Sp1 & 3.30 & 3.93 & 1.22 & 0.981 & 1.11 & 0.934 & 0.619 & 10.1 & 22.2 \\
\hline Sp2 & 3.22 & 4.78 & 1.09 & 1.48 & 1.08 & 1.09 & 0.573 & 9.86 & 23.2 \\
\hline $\mathrm{Sp} 3$ & 2.61 & 3.31 & 0.744 & 0.816 & 0.630 & 1.12 & 0.861 & 14.2 & 24.3 \\
\hline Sp4 & 2.57 & 3.62 & 0.789 & 1.50 & 0.908 & 3.57 & 0.803 & 11.6 & 25.3 \\
\hline Sp5 & 3.56 & 5.49 & 1.34 & 1.51 & 1.52 & 1.31 & 0.710 & 10.2 & 25.6 \\
\hline Sp6 & 2.68 & 3.19 & 0.492 & 2.98 & 0.485 & 0.881 & $<$ LOD & 15.4 & 26.2 \\
\hline Sp7 & 5.84 & 6.07 & 1.41 & 1.47 & 1.26 & 1.26 & 1.08 & 8.77 & 27.2 \\
\hline Sp8 & 6.69 & 6.10 & 1.36 & 1.84 & 1.78 & 0.922 & 0.640 & 9.45 & 28.8 \\
\hline Sp9 & 3.94 & 3.83 & 1.17 & 2.12 & 1.24 & 1.05 & $<$ LOD & 16.3 & 29.7 \\
\hline Sp10 & 4.37 & 7.30 & 1.26 & 1.58 & 1.05 & 2.12 & 1.08 & 12.5 & 31.3 \\
\hline Sp11 & 6.16 & 5.56 & 1.27 & 2.19 & 1.98 & 1.07 & 0.924 & 12.5 & 31.7 \\
\hline Sp12 & 5.57 & 6.10 & 1.29 & 2.34 & 1.60 & 0.973 & 0.939 & 13.1 & 31.9 \\
\hline Sp13 & 4.83 & 4.51 & 1.72 & 1.72 & 1.82 & 1.17 & 0.95 & 16.9 & 33.6 \\
\hline Sp14 & 6.75 & 6.33 & 1.53 & 1.95 & 1.88 & 1.59 & 1.49 & 15.7 & 37.2 \\
\hline Sp15 & 4.39 & 4.92 & 0.931 & 1.25 & 1.53 & 1.15 & 0.786 & 24.9 & 39.9 \\
\hline Sp16 & 4.12 & 4.48 & 1.12 & 1.46 & 1.60 & 1.32 & $<$ LOD & 28.1 & 42.2 \\
\hline Sp17 & 2.94 & 1.72 & 0.842 & 1.22 & 2.00 & 1.05 & 1.18 & 39.2 & 50.1 \\
\hline Sp18 & 3.10 & 4.17 & 0.883 & 3.82 & 0.976 & 2.13 & 0.691 & 47.3 & 63.1 \\
\hline Sp19 & 4.48 & 9.76 & 3.74 & 1.60 & 0.985 & 0.980 & 1.19 & 64.1 & 86.8 \\
\hline S1 & 3.69 & 7.60 & $<\mathrm{LOD}$ & 2.25 & $<$ LOD & 1.56 & $<$ LOD & $<\mathrm{LOD}$ & 15.8 \\
\hline S2 & 7.58 & 10.2 & $<\mathrm{LOD}$ & 6.86 & $<$ LOD & $<$ LOD & $<$ LOD & $<\mathrm{LOD}$ & 25.4 \\
\hline S3 & 4.71 & 5.69 & $<$ LOD & 3.50 & $<$ LOD & 3.38 & $<$ LOD & 10.5 & 28.1 \\
\hline S4 & 2.82 & 4.32 & $<$ LOD & 3.41 & $<$ LOD & $<$ LOD & $<$ LOD & 18.2 & 29.1 \\
\hline S5 & 5.74 & 5.78 & $<$ LOD & 4.83 & $<$ LOD & $<$ LOD & $<$ LOD & 12.6 & 29.3 \\
\hline S6 & 4.37 & 5.16 & $<$ LOD & 4.00 & $<$ LOD & $<$ LOD & $<$ LOD & 16.7 & 30.6 \\
\hline S7 & 3.77 & 6.66 & $<\mathrm{LOD}$ & 5.77 & $<$ LOD & $<$ LOD & $<$ LOD & 14.8 & 31.3 \\
\hline S8 & 6.30 & 9.34 & $<\mathrm{LOD}$ & 5.69 & $<$ LOD & $<$ LOD & $<$ LOD & 15.3 & 37.0 \\
\hline S9 & 6.01 & 9.30 & 1.49 & 4.68 & $<$ LOD & $<$ LOD & 1.36 & 17.2 & 40.3 \\
\hline $\mathrm{S} 10$ & 7.76 & 9.32 & 0.517 & 3.88 & $<$ LOD & 1.83 & 1.06 & 17.6 & 42.1 \\
\hline S11 & 8.28 & 9.16 & $<$ LOD & 7.47 & 0.734 & 6.37 & 0.934 & 13.4 & 46.4 \\
\hline S12 & 6.88 & 10.2 & 0.653 & 4.73 & $<$ LOD & 1.16 & $<$ LOD & 25.3 & 49.1 \\
\hline S13 & 4.92 & 7.10 & $<$ LOD & 8.40 & $<$ LOD & 2.34 & $<$ LOD & 33.9 & 56.9 \\
\hline S14 & 6.21 & 9.06 & 1.16 & 10.1 & 1.67 & 1.23 & 3.77 & 29.0 & 62.2 \\
\hline B1 & 9.65 & 11.6 & 0.351 & 8.89 & 0.544 & 14.3 & 0.539 & 29.6 & 75.4 \\
\hline B2 & 6.98 & 7.50 & 2.27 & 11.1 & 2.46 & 9.38 & 1.61 & 11.9 & 53.2 \\
\hline B3 & 8.99 & 10.3 & $<$ LOD & 4.10 & 0.753 & 12.1 & 2.15 & 23.4 & 61.9 \\
\hline B4 & 11.6 & 10.2 & 1.03 & 5.23 & 0.981 & 13.6 & 1.35 & 42.8 & 86.8 \\
\hline B5 & 15.6 & 11.7 & 2.66 & 7.55 & 2.30 & 19.3 & 1.08 & 25.3 & 85.4 \\
\hline B6 & 9.41 & 11.7 & 1.05 & 9.08 & 1.05 & 13.1 & 0.797 & 23.1 & 69.3 \\
\hline B7 & 5.74 & 8.54 & $<$ LOD & 1.52 & $<$ LOD & 10.7 & 0.193 & 27.1 & 54.0 \\
\hline B8 & 9.43 & 10.7 & 1.09 & 5.13 & 2.85 & 13.4 & 2.26 & 43.7 & 88.6 \\
\hline B9 & 5.61 & 7.99 & 0.396 & 2.81 & 0.502 & 11.1 & 1.43 & 28.3 & 58.1 \\
\hline B10 & 6.38 & 8.37 & 0.604 & 1.93 & 0.443 & 9.87 & 2.58 & 30.0 & 60.2 \\
\hline B11 & 7.42 & 9.46 & $<\mathrm{LOD}$ & 7.38 & 1.73 & 11.9 & 0.752 & 20.7 & 59.4 \\
\hline B12 & 10.7 & 15.9 & 1.75 & 3.30 & 1.22 & 21.9 & 4.54 & 61.3 & 121 \\
\hline B13 & 7.52 & 5.43 & 0.764 & 2.10 & 0.711 & 31.0 & 2.67 & 57.2 & 107 \\
\hline B14 & 15.1 & 18.0 & 1.52 & 4.20 & 2.45 & 25.6 & 4.75 & 45.8 & 117 \\
\hline
\end{tabular}

Sp: Semen pooled samples $\mathrm{S}$ : Semen samples B: Blood samples.

Values $<$ LOD are set to $1 / 2 \mathrm{LOD}$ in the calculation of $\sum \mathrm{PBDE}_{8}$.

PBDEs were $37.4 \mathrm{pg} / \mathrm{g}$ ww and $78.4 \mathrm{pg} / \mathrm{g}$ ww in paired semen and blood samples, respectively. Nonparametric tests showed a significant difference in the concentration level of PBDEs between the paired semen and blood samples $(p=0.001)$. The concentrations of PBDEs in blood samples were about 2 times higher than in semen samples, and the ratio was much lower than the above literature concerning other POPs. This indicate that PBDEs may be more easily transferred into semen than other POPs, such as PCBs and p,p'-DDE. We have no precise explanation for the distribution difference of PBDEs from other POPs in semen and blood. Maybe, the distribution difference was relative to the physical and chemical characteristics of these contaminants. It is interesting that the concentration ratios of blood/semen were different between PBDEs and other POPs, and further research should be performed.

Base on lipid weight, the average concentrations in semen and blood samples were $13.2 \mathrm{ng} / \mathrm{g}$ lipid weight and $22.5 \mathrm{ng} / \mathrm{g}$ lipid weight, respectively. The level of PBDE burden in the male patients from the general population away from e-waste recycling sites, was lower than that in the residents from e-waste recycling sites in Taizhou (Zhao et al., 2010). Furthermore, the PBDE burden of these patients was much lower than among occupational workers (with a mean PBDEs of $600 \mathrm{ng} / \mathrm{g}$ lipid) from Guiyu, as reported by Bi et al. (2007). Nevertheless, the level of PBDE burden in the patient population was higher than those in the general European and Asian populations, which were generally below 5 ng/g lipid (Furst, 2006; Inoue et al., 2006; Lorber, 2008; Schecter et al., 1996, 2003;). Generally, North Americans tend to have higher body burdens of PBDEs than Europeans and Asians (Hites, 2004; Sjödin et al., 2003; Wang et al., 2007). Hites (2004) concluded that the median concentration of PBDEs in the U.S. population was about $35 \mathrm{ng} / \mathrm{g}$ lipid. In this study, PBDE levels of blood and semen in the patient population were slightly less than or comparable to that of the U.S. population. In the present study, the high concentrations of semen and blood samples suggested that more concern should be paid for the potential reproductive risk of Taizhou male population, especially the residents in e-waste recycling sites.

\subsection{PBDE congener pattern in human semen compared with in human blood}

Compared with pooled semen samples, the distribution of PBDE congeners in paired semen samples were similar. As shown in Table 2, the dominant PBDE congener in all samples was BDE-209, which accounted for $43.1 \% \pm 24.8 \%$ and $42.8 \% \pm 18.3 \%$ of $\sum$ PBDEs in paired semen and blood samples, respectively. The finding of BDE-209 as the most dominant congener in human samples was consistent with our previous report regarding Taizhou (Zhao et al., 2010). This result also resembled the congener pattern previously found in human samples from other Asian regions, where BDE-209 had often been found as the most abundant congener (Bi et al., 2007; Inoue et al., 2006; Jin et al., 2009).

PBDE congener patterns in all the semen and blood samples were shown in Fig. 2. The order of most three PBDE congeners except BDE-209 in human semen was BDE$47>$ BDE-28 $>$ BDE-99, while it was BDE-153 $>$ BDE-47 $>$ BDE-28 in blood samples (Fig. 1.). Fig. 2 showed that the concentrations of BDE-28, 47 and 99 in semen and blood samples were nearly equivalent, while the concentrations of BDE-153 and BDE209 were much higher in blood samples than those in the semen samples. The levels of BDE-153 in blood samples were one order of magnitude higher than in semen samples, with median values of 15.5 and $1.23 \mathrm{pg} / \mathrm{g}$ ww in blood and semen samples, 


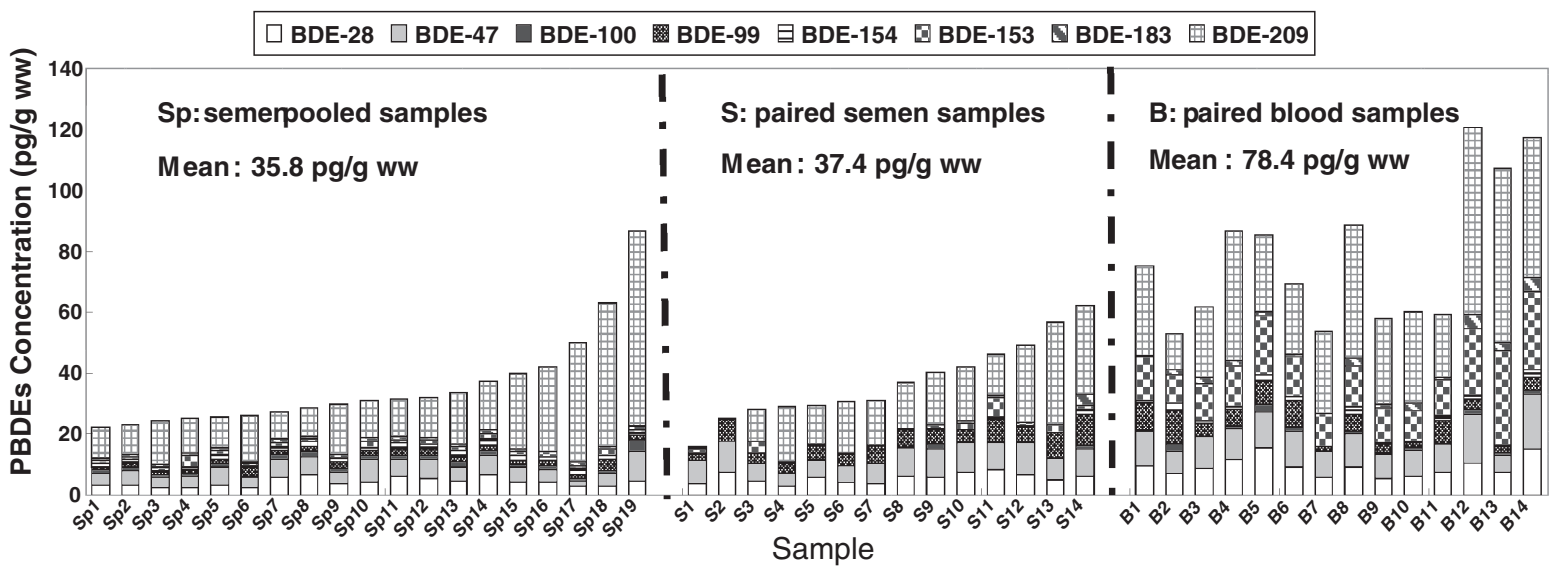

Fig. 1. PBDE congener distribution in all the semen and blood samples.

respectively. It was the difference of BDE-153 and BDE-209 concentrations between blood and semen that resulted in the difference of $\sum$ PBDE concentrations between the two matrices. These results indicated that less BDE-153 and BDE-209 relative to low brominated congeners were transferred to semen, suggesting that low brominated congeners could be more easily transferred to semen than high brominated congeners. Similar phenomenon was found in breast milk, in which low brominated congeners seemed to more easily enter than high brominated congeners (Antignac et al., 2009). Schecter et al. (2010) discussed that the reason for the differential partitioning of PBDE congeners in milk and blood could be due to variation in toxicokinetics, from specific distribution based on molecular size or molecular weight. Maybe, the opinion of Schecter can partly explain the contribution difference of PBDE congeners between semen and blood.

\subsection{Semen as the non-invasive matrix for detecting PBDE burden}

A weak correlation was found between $\sum$ PBDE concentration in paired semen samples and the corresponding concentration in blood samples $(r=0.592, p=0.026)$ (Fig. 3), suggesting that $\sum$ PBDE levels in semen samples could reflect $\sum$ PBDE levels in blood samples to some degree. In addition, a stronger correlation was also significant for BDE-209 in the two matrices $(r=0.784, p=0.026)$ (Fig. 4). Blood is the most commonly used matrix to study the human contamination burden. Some reports have confirmed that contaminants such as PCBs, dioxins and pesticides could enter into human semen (Ensslen et al., 1990; Schlebusch et al., 1989; Schmid et al., 1993; Stache et al., 1989; Szymczynski and Waliszewski, 1981; Trapp et al., 1984), therefore, semen also could be used as a matrix to measure the human burden. Among studies on PBDE burdens in human samples, blood and breast milk are the most used matrices. Semen samples have been never used to investigate human PBDE burden in previous studies. In our study, the presence of PBDEs in human semen, especially with the comparable level in semen and in blood, has suggested that semen could be used to detect PBDE burden in human as a non-invasive matrix.

In some studies regarding human burdens of PBDEs, high brominated congeners including BDE-209 were found in higher concentraions than low brominated congeners

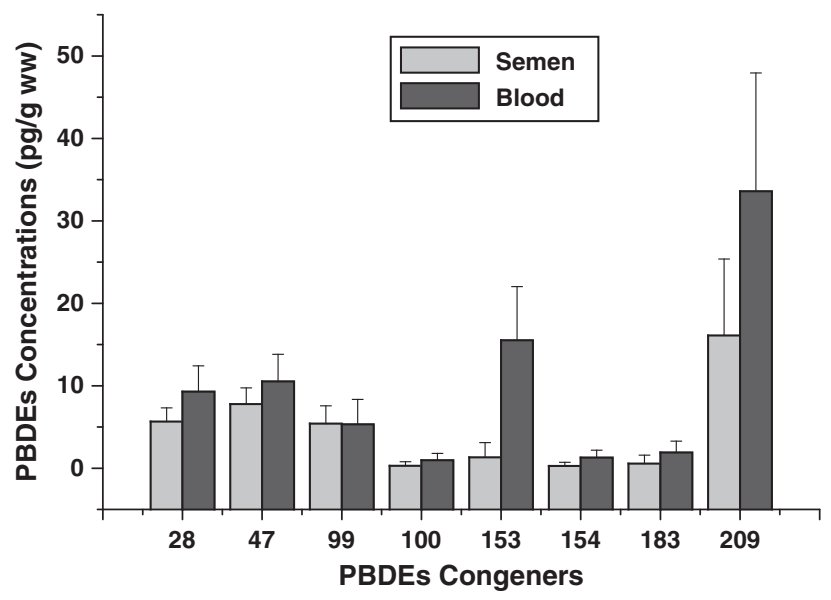

Fig. 2. PBDE congener concentration in semen and blood samples (mean $\pm S D$ ). in blood relative to other matrices (Antignac et al., 2009). In this study, we got the similar results that the contribution percentage of high brominated congeners especially BDE-153 was more in blood samples than in semen samples. Numerous studies have shown that different PBDE congeners have different toxicities due to the corresponding chemical structure. The different distributions of PBDE congeners in the two matrices indicated that semen could more directly reflect human burden of PBDEs in the male reproductive compartment rather than blood. To evaluate the risk of PBDEs for male reproduction, therefore, we suggested that measuring PBDE burden in semen might be more significant than measuring PBDE burden in blood.

\subsection{Association between PBDE levels in semen and patient characteristic}

Because the distribution of PBDEs was not normally distributed, nonparametric methods (Spearman non-parametric correlation) were used to test PBDE relationships with age, abstinence time and body mass index (BMI). No significant association was found between PBDE levels in semen or blood samples with patient characteristics, such as age, abstinence time and BMI.

There was no correlation between PBDEs concentrations and age in the study population, whose ages varied from 20 to 35 years. The observation was consistent with some of previous reports (Johnson-Restrepo et al., 2005; Kunisue et al., 2007; Sjödin et al., 1999; Sjödin et al., 2000; Zhao et al., 2010). Generally, correlation of PBDE burdens with age was explained by different PBDE-exposure times. In Taizhou, the recycling of e-wastes containing PBDEs began from the late 1990s. Some studies have shown that PBDE pollution in Taizhou is mainly from e-waste recycling (Shen et al. 2010; Zhao et al., 2009; Zhao et al., 2010). In this study, therefore, all semen donors had similar life-time exposure independent of the individual's age. So, our result on no agedifference in PBDE burden seemed to be also explained by similar PBDE-exposure time. Recently, several studies reported the correlation between PBDE burden and age

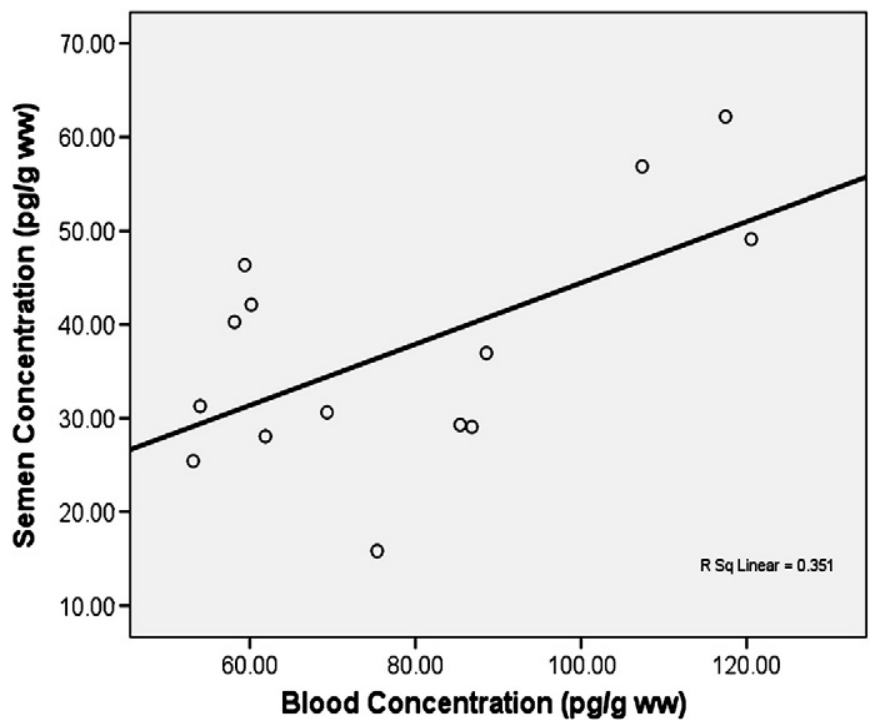

Fig. 3. Relationship between $\sum$ PBDE concentrations in paired semen and blood samples. 


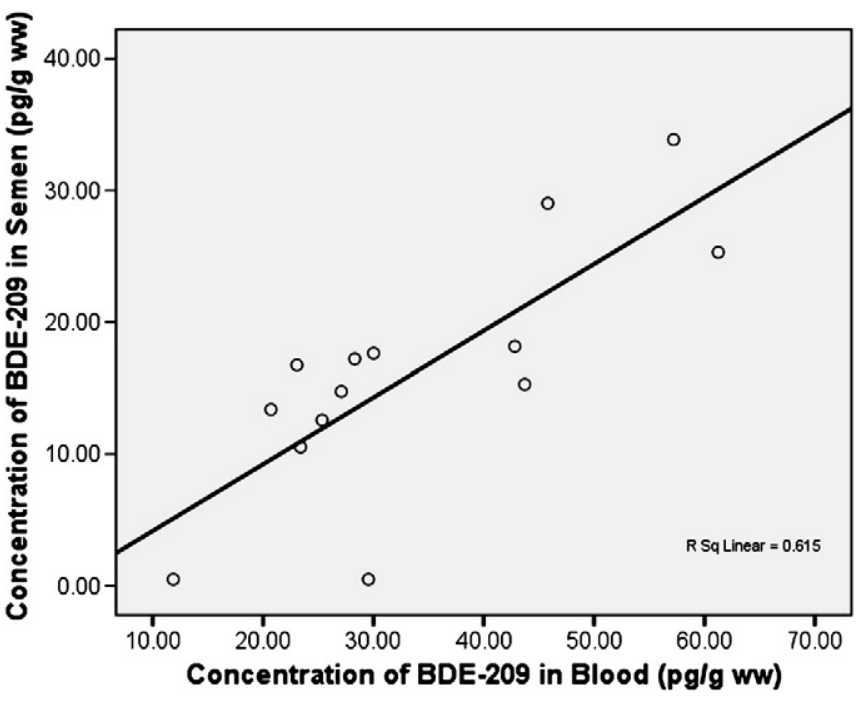

Fig. 4. Relationship between BDE-209 concentrations in paired semen and blood samples.

(Haraguchi et al., 2009; Toms et al., 2008; Toms et al., 2009). In these literatures, however, the age-difference might suggest that PBDE burden depends heavily on exposure background and metabolism rather than exposure time (Johnson-Restrepo et al., 2005; Kunisue et al., 2007; Sjödin et al., 1999; Sjödin et al., 2000; Zhao et al., 2010).

Theoretically, the concentration of contaminants in semen should be positively associated with the duration of abstinence, if contaminants could uninterruptedly enter into semen. In this study, however, no significant correlation between PBDE concentrations and abstinence time, ranging from 1 to 30 days, was found. Although the result needs to be confirmed in a further study at large sample size, it was suggested that PBDE concentration in semen was heavily influenced by other factors rather than abstinence time.

\section{Conclusion}

This study found for the first time the presence of PBDEs in human semen. On a wet weight basis, the PBDE level in semen was two times lower than that of blood. The result suggested that semen as well as blood could be used to investigate PBDE burden in human body as a noninvasive matrix. Furthermore, high brominated congeners contributed less to total PBDEs than low brominated congeners in semen relative to blood, suggesting that low brominated congeners more easily entered male productive compartment than high brominated congeners. To assess the risk for male reproduction, therefore, measuring PBDE burden in semen might be more significant than in blood due to different toxicities of low brominated congeners from high brominated congeners. We found no significant relationship between the PBDE levels and the health parameters such as abstinence time, age and BMI in the present study, further studies at large sample size are needed to verify the results.

\section{Acknowledgments}

We express our heartfelt gratitude to all semen donors. We also thank the doctors in Taizhou Hospital, Zhejiang Province, for their help in collecting semen and blood samples. This work was supported by grants from National Natural Science Foundation of China (21077125 and 20677074) and State Key laboratory of Environmental Chemistry and Ecotoxicology, Research Center for Eco-environmental Sciences, Chinese Academy of Sciences (KF2008-08 and KF2008-11).

\section{References}

Antignac JP, Cariou R, Zalko D, Berrebi A, Cravedi JP, Maume D, Marchand P, Monteau F, Riu A, Andre F, Le Bizec B. Exposure assessment of French women and their newborn to brominated flame retardants: determination of tri- to decapolybromodiphenylethers (PBDE) in maternal adipose tissue, serum, breast milk and cord serum. Environ Pollut 2009;157:164-73.
Aylward LL, Hays SM, LaKind JS, Ryan JJ. Rapid communication: partitioning of persistent lipophilic compounds, including dioxins, between human milk lipid and blood lipid: an initial assessment. J Toxicol Environ Health A 2003;66:1-5.

Bi XH, Thomas GO, Jones KC, Qu WY, Sheng GY, Martin FL, et al. Exposure of electronics dismantling workers to polybrominated diphenyl ethers, polychlorinated biphenyls, and organochlorine pesticides in South China. Environ Sci Technol 2007;41:5647-53.

Dallinga JW, Moonen EJ, Dumoulin JC, Evers JL, Geraedts JP, Kleinjans JC. Decreased human semen quality and organochlorine compounds in blood. Hum Reprod 2002;17:973.

Ensslen SC, Riedel HH, Bluthgen H, Heeschen W. Chlorinated hydrocarbons in seminal plasma and male fertility. Zentralbl Cynakol 1990;112:817-21.

Fowles JR, Fairbrother A, Baecher-Steppan L, Kerkvliet NI. Immunologic and endocrine effects of the flame-retardant pentabromodiphenyl ether (DE-71) in C57BL/6 mice. Toxicology 1994;86:49-61.

Furst P. Dioxins, polychlorinated biphenyls and other organohalogen compounds in human milk. Mol Nutr Food Res 2006;50:922-33.

Haraguchi K, Koizumi A, Inoue K, Harada KH, Hitomi T, Minata M, Tanabe M, Kato Y, Nishimura E, Yamamoto Y, Watanabe T, Takenaka K, Uehara S, Yang HR, Kim MY Moon CS, Kim SH, Wang P, Liu A, Hung NN. Levels and regional trends of persistent organochlorines and polybrominated diphenyl ethers in Asian breast milk demonstrate POPs signatures unique to individual countries. Environ Int 2009;35:1072-9.

Hovander L, Athanasiadou M, Asplund L, Jensen S, Wehler EK. Extraction and cleanup methods for analysis of phenolic and neutral organohalogens in plasma. J Anal Toxicol 2000;24:696-703.

Hites RA. Polybrominated diphenyl ethers in the environment and in people: a metaanalysis of concentrations. Environ Sci Technol 2004;38:945-56.

Inoue K, Harada K, Takenaka K, Uehara S, Kono M, Shimizu T, Takasuga T, Senthilkumar K, Yamashita F, Koizumi A. Levels and concentration ratios of polychlorinated biphenyls and polybrominated diphenyl ethers in serum and breast milk in Japanese mothers. Environ Health Perspect 2006;114: 1179-84.

Jin J, Wang Y, Yang C, Hu J, Liu W, Cui J, Tang X. Polybrominated diphenyl ethers in the serum and breast milk of the resident population from production area, China. Environ Int 2009;35:1048-52.

Johnson-Restrepo B, Kannan K, Rapaport DP, Rodan BD. Polybrominated diphenyl ethers and polychlorinated biphenyls in human adipose tissue from New York Environ Sci Technol 2005;39:5177-82.

Kumar R, Pant N, Srivastava SP. Chlorinated pesticides and heavy metals in human semen. Int J Androl 2000;23:145-9.

Kunisue T, Takayanagi N, Isobe T, Takahashi S, Nose M, Yamada T, Komori H, Arita N Ueda N, Tanabe S. Polybrominated diphenyl ethers and persistent organochlorines in Japanese human adipose tissues. Environ Int 2007;33:1048-56.

Liang SX, Zhao Q Qin ZF, Zhao XR, Yang ZZ, Xu XB. Levels and distribution of polybrominated diphenyl ethers in various tissues of foraging hens from an electronic waste recycling area in South China. Environ Toxicol Chem 2008;27: 1279-83.

Lorber M. Exposure of Americans to polybrominated diphenyl ethers. J Exp Sci Environ Epidemiol 2008:18:2-9.

Magnusdottir EV, Thorsteinsson T, Thorsteinsdottir S, Heimisdottir M, Olafsdottir K Persistent organochlorines, sedentary occupation, obesity and human male subfertility. Hum Reprod 2005;20:208-15.

Pant N, Kumar R, Mathur N, Srivastava SP, Saxena DK, Gujrati VR. Chlorinated pesticides concentration in semen of fertile and infertile men and correlation with sperm quality. Environ Toxicol Pharmacol 2007;23:135-9.

Schecter A, McGee H, Stanley JS, Boggess K, Brandt-Rauf P. Dioxins and dioxin-like chemicals in blood and semen of American Vietnam veterans from the state of Michigan. Am J Ind Med 1996;30:647-54.

Schecter A, Pavuk M, Papke O, Ryan JJ, Birnbaum L, Rosen R. Polybrominated diphenyl ethers (PBDEs) in U.S. mothers' milk. Environ Health Perspect 2003;111:1723-9.

Schecter A, Colacino J, Sjödin A, Needham L, Birnbaum L. Partitioning of polybrominated diphenyl ethers (PBDEs) in serum and milk from the same mothers. Chemosphere 2010;78:1279-84.

Schlebusch H, Wagner U, van der Ven H, Al-Hasani S, Diedrich K, Krebs D. Polychlorinated biphenyls: the occurrence of the main congeners in follicular fluid and sperm fluids. J Clin Chem Clin Biochem 1989;27:663-7.

Schmid S, Pavic N, Tempini A, Linde HH. Polychlorierte biphenyls als sterilitatsursache bei der frau? Gynak-Geburt Rundschau 1993;33:103-6.

Shen H, Ding G, Han G, Wang X, Xu X, Han J, Lou X, Xu C, Cai D, Song Y, Lu W. Distribution of PCDD/Fs, PCBs, PBDEs and organochlorine residues in children's blood from Zhejiang, China. Chemosphere 2010;80:170-5.

Sjödin A, Hagmar L, Klasson-Wehler E, Kronholm-Diab K, Jakobsson E, Bergman A. Flame retardant exposure: polybrominated diphenyl ethers in blood from Swedish workers. Environ Health Perspect 1999;107:643-8.

Sjödin A, Hagmar L, Klasson-Wehler E, Björk J, Bergman A. Influence of the consumption of fatty Baltic Sea fish on plasma levels of halogenated environmental contaminants in Latvian and Swedish men. Environ Health Perspect 2000;108:1035-41.

Sjödin A, Patterson Jr DG, Bergman A. A review on human exposure to brominated flame retardants-particularly polybrominated diphenyl ethers. Environ Int 2003;29:829-39.

Stachel B, Dougherty RC, Lahl U, Schlösser M, Zeschmar B. Toxic environmental chemicals in human semen: analytical method and case studies. Andrologia 1989;21:282-91. 
Szymczynski G, Waliszewski SM. Content of chlorinated pesticides in human semen of a random population. Int J Androl 1981;4:669-74.

Toms LM, Harden F, Paepker O, Hobson P, Ryan JJ, Mueller JF. Higher accumulation of polybrominated diphenyl ethers in infants than in adults. Environ Sci Technol 2008:42:7510-5

Toms LM, Sjödin A, Harden F, Hobson P, Jones R, Edenfield E, Mueller JF. Serum polybrominated diphenyl ether (PBDE) levels are higher in children (2-5 years of age) than in infants and adults. Environ Health Perspect 2009;117:1461-5.

Trapp M, Baukloh V, Bohnet HG, Heeschen W. Pollutants in human follicular fluid. Fertil Steril 1984;42:46-148.

Wang Y, Jiang G, Lam PK, Li A. Polybrominated diphenyl ether in the East Asian environment: a critical review. Environ Int 2007;33:963-73.

Yang ZZ, Zhao XR, Zhao Q, Qin ZF, Qin XF, Xu XB, Jin ZX, Xu CX. Polybrominated diphenyl ethers in leaves and soil from typical electronic waste polluted area in South China. Bull Environ Contam Toxicol 2008;80:340-4.

Younglai EV, Foster WG, Hughes EG, Trim K, Jarrell JF. Levels of contaminants in human follicular fluid, serum, and seminal plasma of couples undergoing in vitro fertilization. Arch Environ Contam Toxicol 2002;43:121-6.
Zhao G, Wang Z, Dong MH, Rao K, Luo J, Wang D, Zha J, Huang S, Xu Y, Ma M. PBBs, PBDEs, and PCBs levels in hair of residents around e-waste disassembly sites in Zhejiang Province, China, and their potential sources. Sci Total Environ 2008;397: 46-57.

Zhao YX, Oin XF, Li Y, Liu PY, Tian M, Yan SS, Qin ZF, Xu XB, Yang YJ. Diffusion of polybrominated diphenyl ether (PBDE) from an e-waste recycling area to the surrounding regions in Southeast China. Chemophere 2009;76:1470-6.

Zhao XR, Qin ZF YZZ, Zhao Q Zhao YX, Qin XF, Zhang YC, Ruan XL, Zhang YF, Xu XB. Dual body burdens of polychlorinated biphenyls and polybrominated diphenyl ethers among local residents in an e-waste recycling region in Southeast China. Chemosphere 2010;78:659-66.

Zhou T, Taylor MM, DeVito MJ, Crofton KM. Developmental exposure to brominated diphenyl ethers results in thyroid hormone disruption. Toxicol Sci 2002;66: 105-16. 